\title{
Competência em informação: o bibliotecário e o processo de definição das necessidades informacionais
}

Jaires Oliveira Santos

Maria Isabel De Jesus Sousa Barreira

Universidade Federal da Bahia - UFBA, Brasil

ORIGINAL

\section{Resumo}

Objetivo. Trata-se de um recorte da investigação de Mestrado desenvolvido no Programa de Pós-graduação em Ciência da Informação da Universidade Federal da Bahia (PPGCI/UFBA). A pesquisa aborda a competência em informação dos egressos do curso de biblioteconomia do nordeste brasileiro. Para a consecução desta, delineou-se como objetivo geral analisar a competência em informação dos egressos do curso de Biblioteconomia da Região Nordeste do Brasil, especificadamente procurou-se caracterizar os mencionados egressos do período de 2004 a 2014 e verificar a capacidade dos egressos para definir as necessidades informacionais.

Metodologia. Trata-se de uma pesquisa descritiva, com método de levantamento (survey), combinando as abordagens quantitativas e qualitativas. O instrumento de coleta de dados foi o questionário Survey, elaborado de acordo com os Padrões da Association of College and Research Libraries (ACRL) e à luz da literatura. A população dessa pesquisa são os egressos de nove Instituições de Ensino Superior (IES) federais que abrigam o curso de Biblioteconomia, entretanto, a amostra constituiu-se de 237 participantes.

Resultados. Os dados foram organizados em cinco categorias temáticas, entretanto, nesse estudo analisar-se-ão as duas primeiras categorias.

Conclusão. Conclui-se, portanto, que de modo geral os egressos adquiriram ao longo de sua formação as competências que são indispensáveis à sua atuação profissional, entretanto, existem aspectos a serem aprimorados.

Palavras-chave

Bibliotecários do Nordeste Brasileiro; Competência em informação; Necessidades informacionais; Padrões ACRL.

\section{Information competence: the librarian and the process of defining information needs}

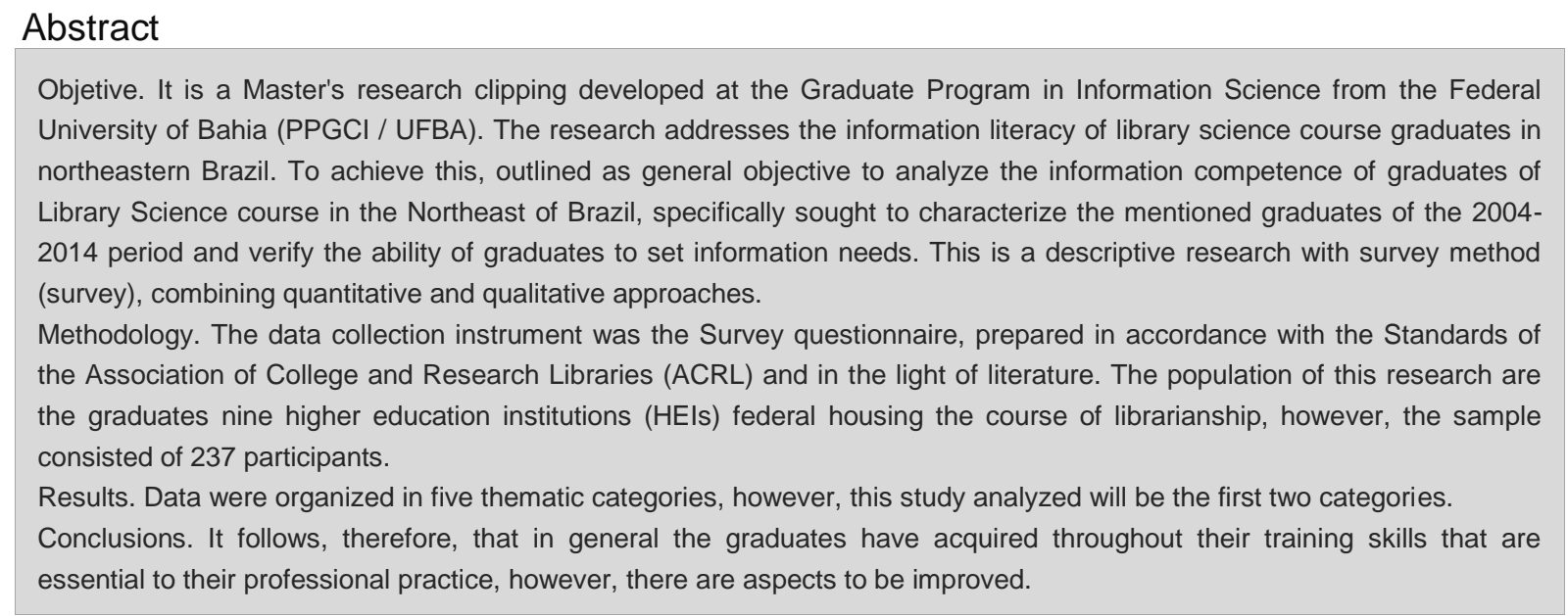




\section{Introdução}

A aceleração dos processos de produção e disseminação da informação exige que os indivíduos possuam um conjunto de habilidades, atitudes, condutas e conhecimentos sobre o universo informacional para que estes se tornem independentes no uso da informação. Lecardelli e Prado (2006, p. 27) ratificam que "[...] o uso e domínio da informação em qualquer formato que se apresenta tornou-se fundamental na sociedade da informação e do conhecimento", ou seja, as pessoas precisam estar aptas para conviver com esse momento de "explosão da informação", estando capacitados para selecionar, avaliar, interpretar e utilizar as fontes de informação habilmente, conhecendo inclusive seus mais variados suportes e formatos.Campello (2008) acrescenta que essas habilidades são denominadas de competência em informação.

O cenário atual e suas exigências contínuas conduzem a Biblioteconomia a aprofundar e ressaltar alguns aspectos educacionais da área, através da promoção e criação de programas de competência em informação, a fim de que os bibliotecários possam adquirir competências que contribuam para sua autonomia e independência no processo de busca para atender às demandas informacionais de seus usuários.

Em face da realidade exposta, surgiram algumas inquietações acerca das habilidades e atitudes inerentes à práxis biblioteconômica na sociedade da informação: a formação atual dos bibliotecários propicia a aquisição de competências necessárias para atuar num mercado cada vez mais exigente? Possuem esses profissionais conhecimentos sobre competência em informação? Utilizam no cotidiano profissional conhecimentos advindos da competência em informação? Esses e outros questionamentos nortearam a questão principal a ser investigada, qual seja: os egressos dos cursos de Biblioteconomia da Região Nordeste do Brasil adquiriram as competências em informação necessárias para atuar profissionalmente? Para responder a esta questão, buscou-se primordialmente analisar a competência em informação dos egressos do curso de Biblioteconomia da Região Nordeste do Brasil e, especificamente, pretendeu-se nessa fase da pesquisa, elucidar dois objetivos da pesquisa, qual seja: caracterizar os mencionados egressos do período de 2004 à 2014 e verificar a capacidade dos egressos para definir as necessidades informacionais, com vistas a atender ao usuário e/ou suas próprias demandas de trabalho. Salienta-se que o recorte temporal, representando a realidade neste contexto especifico, é justificado pelas mudanças curriculares que ocorreram no mencionado período.

Considerando o papel a ser desempenhado pelo bibliotecário no contexto atual, investigar suas competências em informação é relevante, pois permite, dentre outras, a reflexão acerca do ensino do curso na região e a contribuição do mesmo no desenvolvimento das habilidades e competências desses sujeitos durante o processo de formação profissional. Nesse sentido, o relatório Delors (1998) indica que a competência em informação envolve o aprender - referindo-se ao aprendizado ao longo da vida do homem, do seu saber, das suas aptidões e da sua capacidade de discernir e agir no meio social.

Ademais, compreende-se que uma parcela significativa desses profissionais atua em instituições de educação e cultura, o que demanda deles a aquisição de competências e habilidades indispensáveis ao atendimento das necessidades informacionais de seus usuários. Assim, a relevância social desse estudo está assentada na possibilidade de contribuir para o aprimoramento da prática profissional do bibliotecário no processo de aquisição da informação, bem como na perspectiva de potencializar o senso critico dos usuários, tornando-os capazes de utilizar a informação de maneira eficaz. Ao aplicar suas competências e habilidades no ambiente de trabalho, o bibliotecário educará um determinado grupo social para o uso eficiente da informação.

Por outro lado, os resultados dessa pesquisa agregarão novos conhecimentos à Ciência da Informação e quiçá desencadearão futuras investigações sobre a temática da competência em informação, cujas descobertas poderão ser utilizadas na formação dos futuros profissionais da informação. Tal competência, que vai ao encontro das demandas sociais pela informação, realça o espectro social da Ciência da Informação e consequentemente da Biblioteconomia.

O cerne da Ciência da Informação, conforme Almeida (2007), está relacionado ao campo social da produção do conhecimento e as demandas informacionais da sociedade. A diversidade e multiplicidade da informação são as forças determinantes e legitimadoras desta ciência que está imbricada ao conceito de competência em informação. Nesse sentido, Le Coadic (2004) infere que a Ciência da Informação tem como objeto a análise das propriedades da informação e de seus processos de construção, comunicação e uso, o que leva a crer que 
estudar a competência em informação de um determinado grupo social insere-se no universo da Ciência da Informação.

\section{Percurso metodológico}

$\mathrm{O}$ ato de pesquisar demanda do pesquisador múltiplos olhares sobre o objeto investigado. Assim, a presente seção apresenta o caminho trilhado para realizar o estudo, descrevendo os procedimentos adotados com vistas a obtenção dos dados que responderia a questão que norteou a investigação. Nesse segmento, Minayo (1994) corrobora com a assertiva e assevera que o processo investigativo é uma atividade inacabada que continuamente é permeada pela teoria e pela prática, numa constante aproximação com o contexto no qual o objeto está inserido.

\subsection{Universo e amostra}

O universo de uma investigação, segundo Babbie (1999), é a agregação teórica e hipotética dos elementos definidos em um levantamento (survey), não especificado o tempo e o lugar. Portanto, o universo desta pesquisa constitui-se dos egressos do curso de Biblioteconomia da Região Nordeste do Brasil. Incialmente identificou-se os cursos de Biblioteconomia através do portal do Ministério da Educação e Cultura (MEC) a fim de quantificálos para compreender o universo a ser estudado. Deste levantamento foram identificadas 10 (dez) instituições públicas que abrigam os referidos cursos, entretanto, excluiu-se uma, por se tratar de uma instituição estadual, uma vez que a opção foi pelas instituições de ensino do âmbito federal.

Em seus estudos, Babbie (1999) reforça que a população consiste na agregação teoricamente especificada de elementos do mencionado survey, constituindo assim um recorte do universo, no tempo e no espaço. Desse modo, a população objeto desse estudo são os bibliotecários formados em IES federal do Nordeste brasileiro.

Assim sendo, a amostra, intencionalmente definida, foi constituída pelos egressos de Biblioteconomia da Região Nordeste do Brasil de 2004 a 2014, período marcado por mudanças nas matrizes curriculares dos cursos, conforme informações constantes nos sítios das Instituições de Ensino Superior (IES), elencadas a seguir ${ }^{1}$ :

\footnotetext{
1. Universidade Federal de Alagoas (UFAL)

2. Universidade Federal da Bahia (UFBA)

3. Universidade Federal do Cariri (UFCA)

4. Universidade Federal do Ceará (UFC)

5. Universidade Federal do Maranhão (UFMA)

6. Universidade Federal da Paraíba (UFPB)

7. Universidade Federal de Pernambuco (UFPE)

8. Universidade Federal do Rio Grande do Norte (UFRN)

9. Universidade Federal de Sergipe (UFS)
}

\footnotetext{
${ }^{1}$ Nesse estudo optou-se por usar a terminologia Biblioteconomia, mesmo que nos estados da Bahia e Sergipe, o curso esteja cadastrado no MEC como Biblioteconomia e Documentação.
} 
Sobre esse ponto, Marconi e Lakatos (2009) explicam que delimitar uma pesquisa é estabelecer limites para a investigação. A limitação da pesquisa relaciona-se com o aspecto, à extensão e a uma série de outros fatores. Então, além de especificar a delimitação da pesquisa, é preciso saber se a abrangência do estudo recai sobre todo o universo ou apenas sobre uma amostra.

Na presente investigação, o universo considerado foi de 382 egressos, cuja amostra foi constituída por 237 respondentes, formados nas IES federais, cujo critério de inclusão recaiu sobre o quantitativo que respondeu o questionário na íntegra.

\subsection{Estratégias metodológicas}

Para atender as formalidades exigidas pela ciência, a presente investigação foi enquadrada como descritiva, pois, segundo Gil (2008), descreve características de uma população especifica, no caso, os egressos dos cursos de Biblioteconomia do Nordeste, no que tange às competências informacionais. Triviños, (1987) ratifica também que a pesquisa descritiva investiga o maior número possível de informações relativas ao que pretende compreender. Ante essa concepção, essa investigação procura evidenciar elementos que favoreçam uma maior compreensão da competência em informação dos egressos de biblioteconomia do Nordeste brasileiro.

Ainda nessa perspectiva, Barros; Souza (1986) e Bervian; Cervo (1983) são unânimes em afirmar que a pesquisa descritiva é aquela em que o pesquisador observa, registra, analisa e correlaciona fatos ou fenômenos (variáveis) sem manipulá-los, isto é, o pesquisador procura descobrir com que frequência um fenômeno ocorre, sua natureza, características, causas, relações e conexões com outros fenômenos. Além disso, em razão da natureza dos dados, esta investigação se caracteriza como quantitativa e qualitativa. De acordo com Goode e Ratt (1968) apud Oliveira (1997, p. 116), “[...] o que é medido continua a ser uma qualidade”, o que significa dizer que embora exista a tendência de mensuração dos dados, não se exclui a possibilidade de tratá-los qualitativamente. Valentim (2005) afirma ainda que ambas devem ser complementares e não excludentes. Vale dizer que a combinação de técnicas enriquece e amplia a compreensão do fenômeno estudado.

Sobre a escolha da metodologia mais adequada na Ciência da Informação, Mueller (2007, p. 9) diz:

[...] não há, na Ciência da Informação, métodos preferenciais ou abordagens teóricas exclusivas, possibilitando ao pesquisador ampla escolha de métodos e estratégias, talvez refletindo e reforçando a sua condição de disciplina em constante expansão, sem limites definidos.

Nesse sentido, pode-se afirmar que se trata de uma pesquisa descritiva em forma de levantamento ou survey, cujo objetivo é conhecer o comportamento de um determinado grupo de indivíduos. O instrumento de coleta de dados foi o questionário, com características survey (Apêndice A), por possibilitar maior abrangência em número de participantes. Conforme ratifica Radcliff e colaboradores (2007), esse instrumento produz resultados representativos da população que está sendo pesquisada, além da familiaridade que os sujeitos possuem com este tipo de instrumento.

As questões que compuseram o instrumento de coleta de dados foram elaboradas acordo com os padrões da ACRL (2000) e com a literatura que versou sobre a temática, procurando, sobretudo, responder aos objetivos da investigação. Estas foram distribuídas no intuito de estabelecer, a priori, categorias pré-determinadas, a fim de facilitar a apresentação e análise dos dados:

- Perfil dos participantes (questões de 1 a 6);

- Necessidades e identificação das fontes de informação (questões de 7 a 10);

- Estratégias e seleção de recursos (questões de 11 a 14);

- Avaliação da informação (questões de 15 a 17); 
Ressalta-se que foi utilizada a escala Likert, pois esta permite a ordenação de indivíduos através da favorabilidade de sua atitude em relação a determinado objeto, fenômeno ou ação (KIDDER, 1987). De acordo com Gonçalves (2008), a escala Likert é usada para capturar a importância relativa de cada uma das afirmações presentes nas questões.

\subsection{Procedimentos de coleta de dados}

A incursão em campo é o momento em que o pesquisador põe em prática os procedimentos que possibilitarão a aquisição dos dados que responderão aos objetivos propostos (SANTOS, 2007). Nesse estudo, realizou-se um pré-teste, por meio do questionário na versão eletrônica (SurveyMonkey) junto aos bibliotecários que não participaram da amostra, durante o mês de junho de 2015, a fim de averiguar a compreensão dos egressos sobre as questões arroladas, e se necessário realizar adequações pertinentes. Em seguida, identificou-se, nos sites dos cursos de Biblioteconomia das IES federais, os contatos dos coordenadores dos mencionados cursos (e-mail e telefone). Concomitantemente se fez consulta aos sites dos Conselhos Regionais de Biblioteconomia com o propósito de obter informações sobre os egressos registrados nos respectivos conselhos:

- $\quad$ CRB 3 - Ceará (Fortaleza e Cariri), Piauí;

- $\quad$ CRB 4 - Pernambuco e Alagoas;

- $\quad$ CRB 5 - Bahia e Sergipe;

- $\quad$ CRB 15 - Paraíba e Rio Grande do Norte;

- $\quad$ CRB 13 - Maranhão

Para tanto, foi enviado e-mails aos CRBs (Apêndice B) e aos coordenadores dos cursos de Biblioteconomia (Apêndice C), explicitando a pesquisa, e solicitando a colaboração no sentido de intermediar o contato com os egressos. Esse e-mail foi replicado por três semanas consecutivas no mês de julho de 2015. Salienta-se que os movimentos grevistas dos técnicos-administrativos e docentes da IES possivelmente tenham influenciado negativamente. Após essas tentativas, obteve-se respostas apenas dos egressos provenientes do Ceará. Face a esse insucesso, foi realizado contatos telefônicos para os demais conselhos, solicitando o envio do questionário através da "mala direta" para os bibliotecários. Essa ação também não logrou o êxito esperado. Concomitante a essa ação, utilizou-se o Facebook para contactar os egressos. Postou-se o link do questionário nos grupos e páginas que correspondiam às respectivas instituições e ou classe profissional (Apêndice D). Outrossim, usou-se o chat - conversadores online e grupos de discussão para compartilhar o questionário a ser respondido.

Buscou-se, por meio dos Conselhos, obter dados referentes ao quantitativo de bibliotecários registrados nessas instituições, a fim de mensurar o número de sujeitos que compunha o universo total da pesquisa. Entretanto, somente um CRB respondeu à solicitação. Ante a realidade posta, disponibilizou-se o questionário nas redes sociais, com a pretensão de que chegasse ao maior número de egressos possível. Em um período correspondente a dois meses obteve-se 382 respostas (tabela 1), no entanto, excluiu-se 145 delas, em razão da incompletude das respostas. 


\begin{tabular}{|l|c|}
\hline Opçöes de resposta & Respostas \\
\hline Universidade Federal de Alagoas (UFAL) & 14 \\
\hline Universidade Federal da Bahia (UFBA) & 135 \\
\hline Univer sidade Federal do Cariri (UFCA) & 19 \\
\hline Univer sidade Federal do Ceará (UFC) & 53 \\
\hline Universidade Federal do Maranhẩo (UFMA) & 15 \\
\hline Universidade Federal da Paraba (UFPB) & 32 \\
\hline Universidade Federal de Pernambuco (UFPE) & 48 \\
\hline Univer sidade Federal do Rio Grande do Norte (UFRN) & 43 \\
\hline Universidade Federal de Sergipe (UFS) & 23 \\
\hline Total & $\mathbf{3 8 2}$ \\
\hline
\end{tabular}

Fonte: Elaborado pela autora, dados da pesquisa.

Portanto, a amostra da pesquisa constituiu-se de 237 egressos (tabela 2).

Tabela 2 - Total das respostas completas obtidas, com aceitação dos participantes

\begin{tabular}{|l|lr}
\hline Opções de resposta & Respostas & 237 \\
\hline Sim & $\mathbf{1 0 0 , 0 0 \%}$ & 0 \\
\hline \multicolumn{1}{c|}{ Não } & $\mathbf{0 , 0 0 \%}$ & $\mathbf{2 3 7}$ \\
\hline Total & & \\
\hline
\end{tabular}

Fonte: Elaborado pela autora, dados da pesquisa.

De posse dos dados, inúmeras leituras foram realizadas com a finalidade de sistematizar as informações. Assim, os dados foram organizados em tabelas e gráficos com representação numérica, pois, conforme Bardin (2011, p. 131), essas "operações estatísticas simples (percentagens) [...]" permitem estabelecer [...] resultados" que facilitam a análise. Para facilitar a análise e posterior interpretação, optou-se pela análise de conteúdo, por considerar que essa técnica é a que melhor representa a natureza do objeto estudado, em razão da possibilidade de organizar as informações por temas.

Bardin (2011, p. 149), ao referir a Análise de Conteúdo, diz que esta:

[...] assenta implicitamente na crença de que a categorização (passam de dados brutos a dados organizados) não introduz desvios (por excesso ou por recusa) no material, mas que dá a conhecer índices invisíveis, ao nível dos dados brutos (BARDIN, 2011, p.149). 
Em virtude dessa característica é que os dados foram agrupados em categorias temáticas. Estas, segundo Bardin (2011, p. 147), "[...] são rubricas ou classes, as quais reúnem um grupo de elemento [...] sob um título genérico, agrupamento esse efetuado em razão das características comuns desses elementos". As categorias delineadas respondem aos objetivos propostos e foram dispostas da seguinte forma: C1 - perfil dos participantes; C2 - necessidades e identificação da informação; C3 - estratégias e seleção de recursos, C4 avaliação da informação; e C5 - aspectos legais no uso da informação. Ressalta-se que estas foram elaboradas de acordo com os padrões da ACRL, entretanto, excluiu-se o padrão 4.

\section{Competência em informação: aspectos conceituais}

Na sociedade hodierna, o bibliotecário desempenha um papel relevante enquanto agente facilitador do acesso ao conhecimento, ao atender as demandas informacionais dos cidadãos. Para tanto, tem um desafio permanente no próprio processo de formação profissional, que implica na constante atualização, a fim de que possam ser bem sucedidos na sua carreira, por meio da apropriação e desenvolvimento de competências em informação. Santos (2000) esclarece que, para alcançar tal pretensão, o bibliotecário que considerar a educação continuada como uma meta permanente terá maiores oportunidades no mercado de trabalho.

Investigar a competência em informação parece ser um caminho para a compreensão do conjunto de conhecimentos, atitudes e habilidades inerentes ao saber e fazer da Biblioteconomia. Nessa direção, é relevante revisitar o conceito de competência, haja vista que o mercado de trabalho, na dinâmica de suas oportunidades, tem exigido uma demanda crescente por profissionais bibliotecários competentes em informação para disponibilizar a informação com êxito aos usuários.

As discussões acerca dos conceitos de competências e habilidades tem sido recorrente na área da $\mathrm{Cl}$, cujos conceitos são entendidos por estudiosos como interligados. Segundo Santiago (2012), a diferença entre as duas terminologias consiste em que a primeira se relaciona com o "saber" e a segunda, com o "fazer". Nesse contexto, Bordoni (2003) acrescenta que Competência consiste no desenvolvimento de soluções inéditas, criativas e eficazes para novos problemas, e as habilidades estão relacionadas ao saber fazer.

A competência, segundo França (1998), pode ser compreendida como um conjunto dinâmico e integrado de conhecimento, valores, habilidades, compreensão, interesses e atitudes. Em geral o termo é usado para designar o sujeito capaz de resolver determinados problemas, obtendo sempre os resultados esperados.

Para ilustrar o conceito anteriormente mencionado, Amatucci (2000) citando Le Boterf (1995), apresenta um diagrama em que expressa as relações que se estabelecem a partir do termo competência:

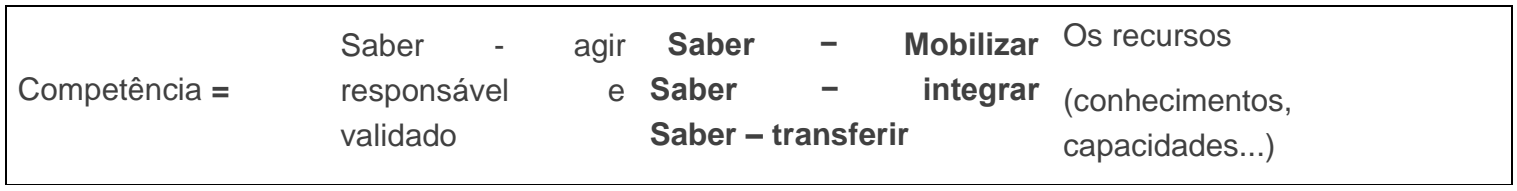

Fonte: (LE BOTERF, 1995, p. 33 apud AMATUCCI, 2000, p. 80, grifos do autor)

A competência em informação originada do termo information literacy (competência em informação) surgiu na década de 1970, com Zurikowski (1974), a partir do seu relatório "The Information Service Environment Relationships and Priorities", no qual consta que "pessoas treinadas para a utilização de fontes de informação em seu trabalho podem ser chamadas de competente informacional". Este conceito à época trouxe uma nova compreensão/reflexão sobre a informação.

Na década de 1990, a Australian School Library Association (ASLA) define competência em informação como: 
[...] sinônimo de saber como aprender. [...] é uma via de empoderamento pessoal. Ela habilita às pessoas verificarem e refutarem opiniões especializadas e tornarem-se independentes na busca da verdade. (ASLA, 1994, apud BUNDY, 2004, p. 5, tradução nossa).

Após vinte anos, o compêndio editado por Bundy, intitulado Australian and New Zealand Institute for Information Literacy (ANZIIL), apresenta uma definição para competência em informação como sendo "[...] a compreensão de um conjunto de habilidades que capacita os indivíduos a reconhecerem o quanto a informação é necessária e a respectiva capacidade de localizá-la, avaliá-la e usá-la efetivamente." (BUNDY, 2004, p. 3, tradução nossa).

A competência em informação, objeto deste estudo, extrapola o conceito laico e mais trivial do termo competência, o qual the conferiu popularidade e que está atrelado ao conceito de ter ou obter aptidão para realizar determinada tarefa. Nessa linha, o seu antônimo, "incompetência", costuma ter um sentido depreciativo ao indivíduo, significando que ele não tem capacidade, habilidade e conhecimento para realizar determinada tarefa. No contexto atual, o conceito de competência tem sido ampliado em diferentes cenários, sejam eles acadêmicos e/ou empresariais. Para Fleury e Fleury, (2001, grifos dos autores), o panorama conceitual do tema competência sugere a necessidade de constante diálogo, ou trocas de ideias, no rumo de sua acepção emergente em diferentes espaços:

Nos últimos anos, o tema competência, seu desenvolvimento, sua gestão, entrou para a pauta das discussões acadêmicas e empresariais, associado a diferentes instâncias de compreensão: no nível da pessoa (a competência do indivíduo), das organizações (as core competences) e dos países (sistemas educacionais e formação de competências).

Desse modo, a competência em informação é um conceito que permeia os circuitos acadêmicos, resultando na produção de livros, dissertações e teses. Vale salientar que ela passou a ser considerada pela área de administração como um conceito-chave e importante ao diferencial, tanto empresarial como profissional, diante de um mercado que evolui constantemente no cenário da Sociedade da Informação.

A competência em informação representa uma área de estudo na $\mathrm{Cl}$ e áreas afins, com interface em outras áreas do conhecimento: a Educação, as Ciências Sociais, a Psicologia Cognitiva, a Comunicação, o Marketing, dentre outras (HATSCHBACH; OLINTO, 2008). Diante da amplitude do termo, percebe-se a relevância de estudos, cujas abordagens estejam centradas na competência para o uso da informação.

A literatura sobre competência em informação e sua avaliação tem sido desenvolvida na esfera internacional, e, no Brasil, foi contemplada em linhas de pesquisas e dissertações na área da Cl. Já no âmbito dos profissionais bibliotecários, poucos trabalhos foram identificados, tais como Coelho (2008); Mata (2009); Santos (2011), Santiago (2012), o que evidencia a necessidade de estudos sobre a temática.

Os estudos de Webber e Johnston (2000, p. 387, tradução nossa), demostram a coesão da $\mathrm{Cl}$ com a competência em informação:

O Instituto dos Cientistas da informação delineou os critérios para a ciência da informação (os quais são usados para validação do curso). Ele começa a descrição detalhada da área a partir do núcleo (ciência da informação) com a definição: 'A teoria e a prática de criar, adquirir, avaliar e validar, organizar, armazenar, transmitir, recuperando e divulgando informações'. Esta declaração nuclear, conforme descrita, adequa-se com os principais recursos que a maioria dos comentaristas identifica para competência em informação.

A competência em informação encontrou no Brasil um campo amplo e fértil para investigação: tem seu escopo trilhando pelos caminhos da melhor qualificação acadêmica e profissional, e sua adequação às demandas informacionais, num mercado que se amplia em diversidade de formatos, suportes e meios de comunicação e volume de informação. Tal diversidade oportuniza as instituições de ensino e aos profissionais o desafio de estarem dispostos e abertos a desenvolver a competência em informação - de aprender, assimilar e dominar o conhecimento, com autonomia, sendo capaz, no final deste processo, de ter a habilidade de transferir a informação aos usuários de forma satisfatória. 
Para ampliar o escopo da discussão, é relevante revisitar os conceitos relacionados aos desafios profissionais da $\mathrm{Cl}$ na perspectiva da formação do Bibliotecário.

\title{
2.1 Formação do bibliotecário: desafios profissionais na sociedade da informação
}

Ao evocar as atividades inerentes ao bibliotecário ao longo dos tempos, nota-se que seu perfil profissional esteve atrelado a sua própria formação "polarizada entre a erudição e a técnica" (FONSECA, 2007, p. 97), sendo o primeiro aspecto mais antigo e o segundo desenvolvido meio século depois, por volta de 1880 , nos Estados Unidos.

Fonseca (2007), dialogando com Ortega y Gasset, menciona que o Bibliotecário seria o filtro entre os livros e o homem. Nessa direção, foi delineada a nova missão desse profissional, que encontraria na tecnologia um novo e ágil instrumento de trabalho. O próprio surgimento da $\mathrm{Cl}$ traz novas perspectivas para a profissão, conforme acrescenta Le Coadic (1996, p. 26, grifos do autor):

\begin{abstract}
DE PRÁTICA de organização, a ciência da informação tornou-se, portanto, uma ciência social rigorosa que se apoia também em uma tecnologia rigorosa. Tem por estudo das propriedades gerais da informação (natureza, gênese, efeitos), ou seja, mais precisamente: [...] conceber os sistemas (as coleções compostas de objetos, as exposições feitas com tais objetos, bem como seu exame e manipulação) que permitem sua comunicação, uso e armazenamento.
\end{abstract}

A profissão de bibliotecário acompanhou o dinamismo dos meios e formas de comunicação que ocorreram em meio à explosão da informação. Le Coadic (1996) esclarece esse pensamento ao inferir que a convergência dos objetos de estudo, bem como o crescimento da produção intelectual, contribuem para os elevados fluxos da informação, que determinam a quantidade de informação por unidade de tempo. Tal explosão informacional pósrevoluções, francesa e industrial, deu visibilidade e uma nova dimensão social a profissão de bibliotecário. $O$ relatório da Special Librarians Association (SLA) apresenta as competências emergentes para os bibliotecários do século XXI, sugerindo o conhecimento do perfil do público usuário, a compreensão de suas demandas informacionais, bem como apropriar-se dos assuntos e temas mais pesquisados.

O relatório diz que a relevância desse profissional decorre do "conhecimento profundo em recursos informacionais impressos e eletrônicos e a capacidade de desenvolver e administrar serviços de informação que atendam as necessidades de grupos de usuários." (COMPETÊNCIAS..., 1996). Adequar-se às mudanças sociais tem sido uma atitude adotada pelos bibliotecários ao longo da existência dessa profissão. A SLA destaca que, entre as principais transformações ocorridas nos últimos anos, destacam-se três: a transição do papel para a mídia eletrônica, o aumento da demanda por responsabilidade, e as novas formas de organização do trabalho. Aliados a fatores decorrentes da evolução da sociedade como a globalização, o uso das novas TIC, a necessidade de medir o capital intelectual e a produtividade dos trabalhadores, bem como a gestão do conhecimento, os quais impulsionam a profissão a constantes atualizações.

O bibliotecário está inserido nessa perspectiva de mudança e diversidade não somente de suporte, mas também na própria dinâmica dos centros de informação, cabendo-lhe desenvolver conhecimentos técnicos e administrativos para estabelecer diretrizes, desenvolver habilidades de liderança e obter competências para traçar metas, estabelecer planos e políticas institucionais no que concerne aos serviços biblioteconômicos, atendimento ao público e gestão da informação.

$\mathrm{Na}$ atualidade, a competência em informação requerida ao bibliotecário pode incluir diversas atividades: disseminação da informação, a elaboração de projetos, a criação de novos produtos informacionais e a adaptação dos recursos já disponíveis na biblioteca, incluindo o uso das redes sociais, com a finalidade de atender melhor as demandas informacionais dos cidadãos e ser um elemento de aproximação da instituição à nova geração de usuários, bem como criar um espaço para realizar o marketing institucional, a difusão dos acervos e eventos culturais.

Castells (2006), sobre esse contexto, afirma que, na era da conectividade, onde a nova geração passa a maior parte do seu tempo conectada às redes sociais, às instituições culturais, arquivos, bibliotecas, centros de 
documentação e museus o desafio de aproveitar o ciberespaço para difusão e marketing institucional, além de buscar uma aproximação ao público usuário, utilizando os recursos tecnológicos e a gratuidade da plataforma Web 2.0, Facebook, Twitter, blogs e sites.

Salienta-se que o uso de novas tecnologias depende de recursos materiais, humanos e vontade política dos gestores. É possível perceber um esforço das bibliotecas em manter um computador conectado a rede mundial Internet. A tarefa social de alfabetização digital está associada e depende diretamente da competência em informação dos bibliotecários, um fato que pode ser percebido na dificuldade dos profissionais mais antigos, frente às novas gerações, onde o uso do computador e da Internet é algo corriqueiro.

O bibliotecário tem à sua frente um campo de constante autoaprendizado a ser explorado especialmente no que tange a otimização dos recursos da web, em conexão com os serviços que uma biblioteca oferece. Ao efetivar essa missão, o profissional tende a aprimorar-se também, conforme salienta os estudos de Freire (1980), ao ressaltar que "educar é conscientizar" na perspectiva da pedagogia progressista do aprender aprendendo, enquanto transmite informação que se transforma em conhecimento.

O processo educativo é um contínuo no espaço social. Nesse sentido, Brandão (1985, p.7) diz que:

Ninguém escapa da educação. Em casa, na rua, na igreja ou na escola, de um modo ou de muitos, todos nós envolvemos pedaços da vida com ela: para aprender, para ensinar, para aprender ensinar, para saber, para fazer, para ser ou conviver, todos os dias misturamos a vida com a educação.

Infere-se que há a necessidade de desenvolver uma conscientização social e profissional, no qual o bibliotecário, agente e mediador da informação, seja um ator social que colabora conscientemente no processo de formação da competência em informação e aprendizado dos usuários no que tange ao saber buscar, acessar, avaliar pertinência e usar a informação exitosamente. Nesse sentido, Freire (1980, p. 25) oferece uma contribuição acerca da dinâmica da conscientização:

Ao ouvir pela primeira vez a palavra conscientização, percebi imediatamente a profundidade de seu significado, porque estou absolutamente convencido de que a educação como prática da liberdade, é um ato de conhecimento, uma aproximação crítica da realidade [...]. Ao nível espontâneo, o homem ao aproximar-se da realidade faz simplesmente a experiência da realidade na qual está e procura. Esta tomada de consciência não é ainda a conscientização, porque esta consiste no desenvolvimento crítico da tomada de consciência.

Essa prática pode oportunizar a pedagogia do aprender a aprender, juntos, pela via da intercomunicação pessoa a pessoa - interagindo com os usuários - frente à nova realidade da conectividade, propiciados pelas TIC (emails, resposta aos comentários postados nas redes sociais e blogs).

Assim, ao buscar informar e conscientizar os usuários da acessibilidade dos recursos informacionais disponíveis na Internet, o bibliotecário não só colabora na aprendizagem do público, mas também no seu autoaprendizado e aperfeiçoamento da competência em informação.

\section{Resultados: apresentação e discussão}

Para responder aos objetivos pretendidos por esta investigação e proporcionar organização e clareza quanto aos dados oriundos da pesquisa de campo, foram delineadas cinco categorias de análise, identificadas como $\mathrm{C} 1$ a C5: perfil dos participantes, necessidades e identificação da informação, estratégias e seleção de recursos, avaliação da informação e aspectos legais no uso da informação, respectivamente. Nesse artigo, apresentar-seão as duas primeiras categorias.

A C1 apresenta a caracterização do perfil dos participantes da pesquisa, com a finalidade de atender ao primeiro objetivo. Nessa etapa explicitou-se qual a instituição e o período que esses bibliotecários se formaram, 
se mantinham o hábito de frequentar o espaço da biblioteca antes de ingressar no curso, em qual tipo de escola cursou o ensino básico e sua preocupação com a educação continuada. Sobre esse tipo de categoria, Fine e colaboradores (2007) ratificam a importância de se compreender o contexto e as características dos sujeitos estudados, a fim de oportunizar uma análise mais coerente dos dados.

Os resultados demonstram que $38 \%$ dos participantes da pesquisa cursaram Biblioteconomia na UFBA, seguido da UFC-Fortaleza, que totalizou $12 \%$ da amostra, e UFPB, UFRN e UFPE (11\%). Infere-se que o significativo percentual de respostas advindas dos bibliotecários da Bahia justifica-se pelo fato de que estes são egressos da UFBA e, portanto, com maior acessibilidade e contato com a pesquisadora, especialmente através das redes sociais. Por outro lado, salienta-se que o instrumento de coleta de dados foi enviado por meio dos mesmos mecanismos e em igual intensidade para a população investigada (replicado a cada dez días), com o intuito de obter o maior número de respostas possível.

Ao analisar a formação dos participantes, constatou-se que os egressos do curso no período correspondente a 2004-2010 (Gráfico 1) totalizaram mais da metade dos participantes (81\%), o que oportuniza compreender que estes bibliotecários provavelmente já atuam no mercado de trabalho há pelo menos cinco anos. Pesquisas realizadas por Santos e Barreira (2014), com os profissionais formados na Bahia, ratificam esse tempo considerável de atuação do bibliotecário no mercado de trabalho, tratando-se, portanto, de um campo de trabalho promissor.

A pesquisa abrange egressos dos últimos quatorze anos, o que leva a crer que possuam familiaridade com o uso dos recursos oriundos dos avanços das TIC, uma vez que conteúdos que abordam esses conhecimentos estão inseridos no campo de estudo da Biblioteconomia e da $\mathrm{Cl}$, e, portanto, fizeram parte do processo formativo desses profissionais. Nesse ponto, Le Boterf $(2003$, p. 13) diz que "o saber combinatório está no centro de todas as competências", isto é, quanto mais o bibliotecário combina saberes, maior será a sua competência. Essa combinação no contexto da sociedade da informação certamente inclui o uso de recursos tecnológicos.

\section{Gráfico 1 - Ano de egresso no curso de Biblioteconomia}

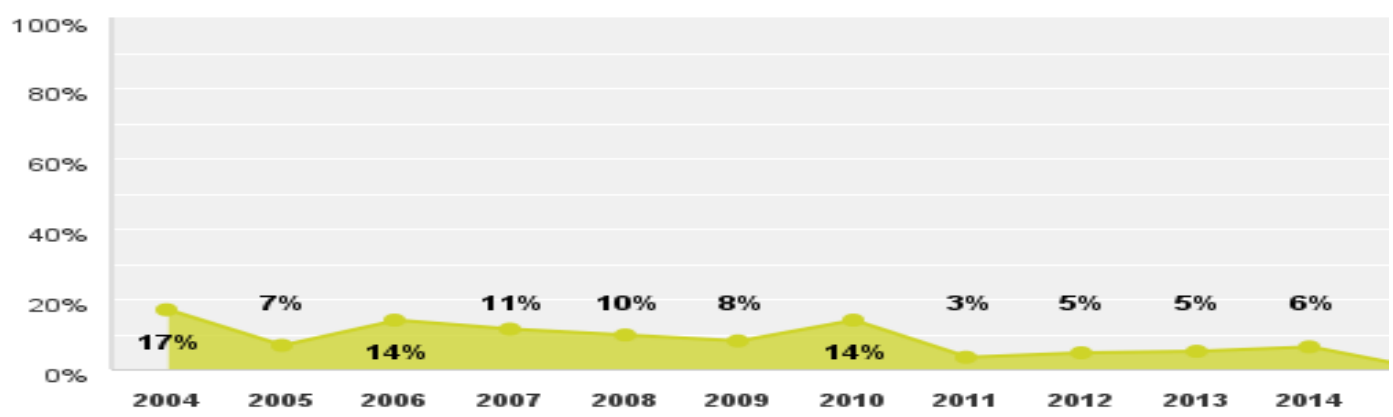

Fonte: Elaborado pela autora, dados da pesquisa.

A frequência dos participantes em bibliotecas antes de ingressar no curso de Biblioteconomia foi uma das curiosidades desse estudo, a fim de verificar uma possível familiaridade dos participantes com o ambiente, antes mesmo de tornar-se um profissional. Os resultados mostraram que a maioria dos bibliotecários formados em IES Federais no Nordeste brasileiro costumava frequentar bibliotecas (73\%). Assim sendo, depreende-se que esses profissionais, mesmo que implicitamente, compreendiam que "para ser competente em todas as atividades da vida é necessário dispor de conhecimentos" (ZABALA; ARNAU, 2010, p. 49), e isso inclui as situações que demandam dos sujeitos procurar, acessar e usar a informação eficientemente e agregando para si conhecimento. Sobre esse processo, Varela, (2006, p.16) compreende que há uma: 
[...] busca constante por novos conhecimentos que demandam interpretar e compreender o mundo: mentes que se antecipam, pessoas autônomas no pensar, sentir e fazer, com a capacidade de julgar situações, baseando-se em ideias e em fatos.

A atitude dos egressos evidenciada no estudo leva a reflexão de que ao visitar esses espaços culturais, talvez esses profissionais envolviam-se na perspectiva de ver-se at quod location, contribuindo de forma significativa para melhoria e reconhecimento da práxis biblioteconômica, por meio do aprendizado ao longo da vida.

\section{Gráfico 2 - Frequência em Bibliotecas, antes do ingresso no curso}

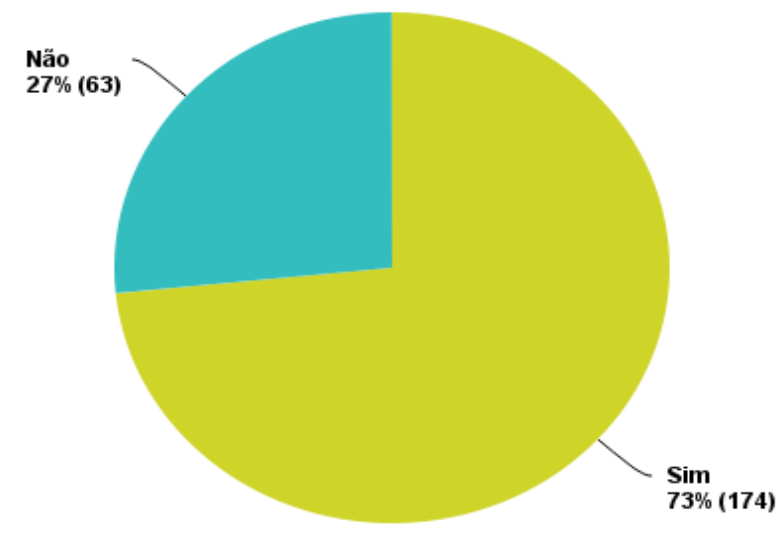

Fonte: Elaborado pela autora, dados da pesquisa.

Inquiriu-se aos profissionais investigados qual a instituição de ensino que cursaram o ensino básico. Os resultados revelaram que $67 \%$ dos respondentes cursaram ensino básico em instituições públicas, enquanto que os demais (33\%) são provenientes da escola particular. Nessa direção, os estudos de Mata (2009), realizados no Sudeste com estudantes de Biblioteconomia, demonstraram que $73 \%$ dos respondentes foram oriundos de escolas públicas, retratando que, de uma forma geral, e respeitando as particularidades das regiões e o lapso temporal que separam as pesquisas, confirma a prevalência dos alunos oriundos do ensino público para cursar Biblioteconomia.

Para finalizar a categoria que buscou caracterizar os participantes da pesquisa, buscou-se, porquanto, compreender a realidade dos participantes em relação à sua preocupação com a educação continuada (especialização, mestrado, doutorado e pós-doutorado). Os dados revelaram que os profissionais investigados preocupam-se com a capacitação profissional, uma vez que mais da metade (128) cursaram ou cursam um tipo de pós-graduação (especialização).

Assim sendo, o bibliotecário está considerando a educação continuada como uma meta permanente, pois, desta forma, terá maiores oportunidades no mercado de trabalho, especialmente quando estimula o desenvolvimento de suas competências e habilidades (SANTOS, 2000).

Prosdócimo e Ohira (2000) ressaltam que "a Educação continuada prepara o indivíduo para executar melhor aquilo que já realiza, focalizar o como fazer, capacitando-o para atuar na realidade atual, como também para o futuro." Por outro lado, Valentim (2002) enfatiza que a responsabilidade de capacitar após sua saída da escola é papel do próprio profissional. Há de se ressaltar que desse total existe ainda aqueles que cursaram ou cursam mestrado e doutorado $(54,9)$ respectivamente, o que reforça a percepção de que os egressos do curso de 
Biblioteconomia no período analisado procuram efetivamente qualificar-se para atender as exigências do mercado de trabalho.

Salienta-se que, neste processo, é relevante que os cursos de Biblioteconomia ofereçam extensão universitária, bem como cursos de pós-graduação lato sensu (especialização) e stricto sensu - mestrado e doutorado, a fim de oportunizar aos egressos a participação na educação continuada (CUNHA, 1984).

Infere-se que esse processo de educação continuada irá favorecer a aquisição de competências para que os profissionais possam identificar as necessidades informacionais de seus usuários com êxito e viabilize a satisfação da mencionada necessidade.

Nessa categoria (C2), buscou-se perceber as atitudes dos sujeitos investigados mediante uma necessidade informacional, que inclui a identificação das fontes de informação, que visam contemplar prontamente a necessidade do consulente e/ou sua própria demanda, quando se trata de uma pesquisa para desenvolvimento de sua atividade laboral. Os resultados esperados com esta categoria de análise estão em consonância com o padrão 1 da ACRL (2000) e procuram responder ao segundo objetivo deste estudo, qual seja, analisar a capacidade dos egressos para definir as necessidades informacionais

Os dados evidenciados denotam que mais da metade dos participantes sempre dialogam com seu usuário, procurando determinar a sua real necessidade de informação (66,7\%); selecionam as fontes possíveis de atender a necessidade informacional do consulente (60,2\%); identificam termos que possam descrever a informação necessitada (57,4\%); e localizam fontes solicitadas e outras que contemplem a informação desejada (56,5\%). Assim sendo, os resultados dessa investigação ratificam as competências expressas nos indicadores de desempenho estabelecidos pela ACRL (2000), denotando que os egressos do curso de Biblioteconomia do Nordeste do Brasil atendem as expectativas reiteradas pelo referido padrão de avaliação de competências.

Percebe-se, por outro lado, que as atitudes inerentes à exploração de diferentes fontes de informação, sejam elas em suporte tradicional e digital, correspondeu a um percentual inferior em relação às demais atitudes elencadas (45\%), o que leva a crer que, mesmo se tratando de egressos, em sua maioria, da primeira década dos anos 2000, período em que já se observava o uso constante das TIC, os profissionais estudados retratam certa timidez no trato com as mencionadas tecnologias. Diante desse contexto, compreende-se que esses profissionais talvez não tenham efetivamente se apropriado das possiblidades que as tecnologias suscitam à sua práxis. Nesse ponto, Borges (2013) diz que, se o indivíduo não souber aplicar competências operacionais, que inclui operar computadores, navegadores, mecanismos de comunicação interligados, terá dificuldades em acessar a informação desejada.

Para sanar as necessidades informacionais, usam-se diferentes estratégias para alcançar o fim pretendido. Desse modo, é salutar que o profissional possua uma atitude que viabilize a adoção de mecanismos que propiciem o refinamento das questões levantadas pelo consulente.

Nessa perspectiva, percebeu-se que parte significativa dos bibliotecários estudados, procuram agregar novas informações, a fim de responder o mais exato possível às inquietações dos usuários e/ou sua própria demanda, haja vista o expressivo percentual evidenciado nos dados. Percebe-se, ainda, a preocupação desses profissionais em adotar ações que visem interpretar as reais necessidades informacionais.

Assim sendo, infere-se que os bibliotecários egressos das IES federais do Nordeste brasileiro usam um conjunto de conhecimentos, habilidades, atitudes necessárias para executar as diversas tarefas oriundas do cotidiano profissional. Uribe (2015) complementa que a competência exige uma combinação de saber, saber fazer, saber ser - informações, habilidades e atitudes técnico, metodológico, social e participativo. Sobre esse aspecto, Le Boterf (2003) e Uribe (2015) tem a mesma compreensão sobre o significado do termo competência, isto é, o uso de saberes combinados e integrados na prática profissional.

Essa investigação buscou averiguar a capacidade dos bibliotecários de identificar os tipos de fontes de informação. Aqui inclui o conjunto de atitudes interligadas com os conhecimentos adquiridos ao longo da sua vida/formação, a fim de que possam, prontamente, identificar a categoria informacional a ser acessada para sanar uma necessidade de informação.

Os dados revelaram que um quantitativo significativo (67\%) dos partícipes não conseguiram, por meio de uma situação profissional corriqueira, identificar corretamente a fonte secundária, o que demonstra uma possível lacuna na aprendizagem durante o processo de sua formação acadêmica. Esse percentual vai de encontro aos resultados esperados pelos indicadores de desempenho do padrão I de avaliação da competência em 
informação da ACRL (2000), qual seja, a identificação e a diferenciação da variedade dos tipos de fontes de informação existentes.

Ainda nesse contexto, apresentou-se exemplos dos tipos de fontes de informação para que os sujeitos investigados pudessem atribuir à denominação correta: fontes primárias, secundárias e terciárias (Gráfico 3). Segundo Mueller (2007), as fontes primárias são aquelas resultantes da interferência direta do autor. Ao identificar tais fontes, os egressos (67\%) afirmaram que livros, dissertações e teses constituem-se fontes primárias, entretanto o quantitativo de $29 \%$ atribuiu bibliografias, dicionários e enciclopédias como primárias.

Não obstante, houve um percentual semelhante quando da identificação das fontes secundárias - que buscam facilitar o uso do conhecimento disperso nas fontes primárias, com organização filtrada, adequada à sua finalidade (MUELLER, 2000), isto é, 67\% responderam corretamente como sendo bibliografias, dicionários e enciclopédias, outros $25 \%$ indicaram como sendo livros, dissertações e teses. Diante desses resultados, percebe-se que aproximadamente $1 / 4$ desses profissionais não conseguem distinguir fontes primárias das secundárias, o que pode refletir no atendimento às demandas informacionais dos consulentes, especialmente, no que se refere à indicação de fontes que possivelmente não responderão exitosamente à mencionada demanda.

Em se tratando das fontes terciárias, que compreendem uma espécie de guia para o usuário alcançar as fontes primárias e secundárias (MUELLER, 2000), percebeu-se certa facilidade de identificação pelos respondentes $(88 \%)$, o que demonstra uma maior familiaridade com esse tipo de fonte, qual sejam, bibliografias de bibliografias, catálogos de catálogos de bibliotecas e diretórios.

\section{Gráfico 3 - Identificação das Fontes de Informação}

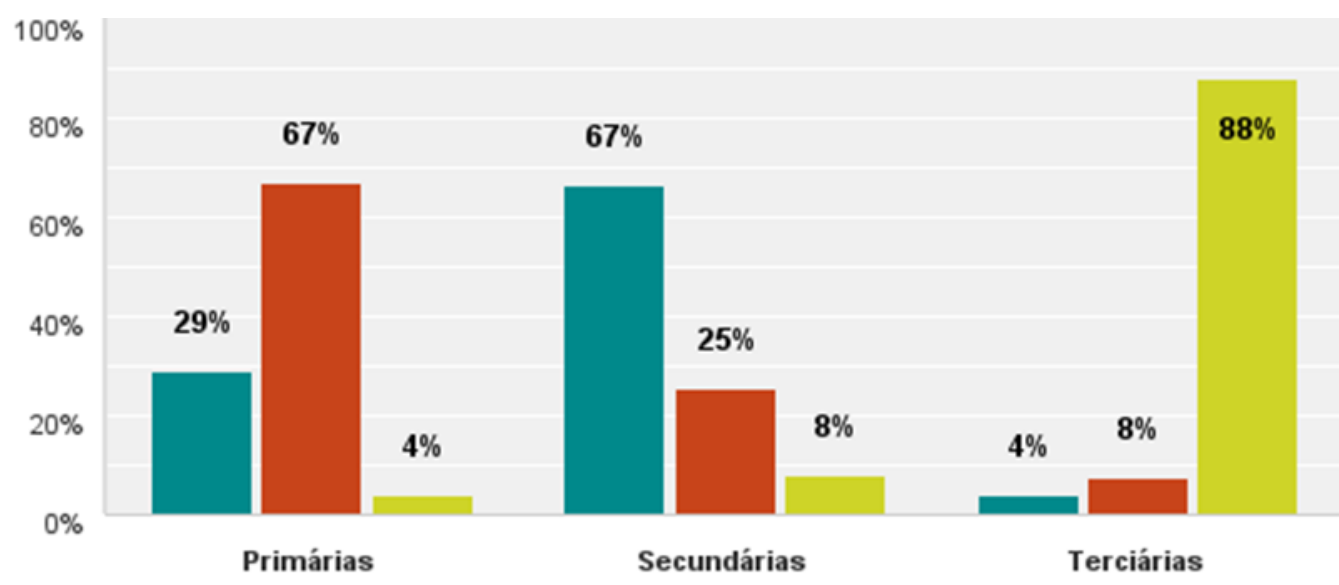

\footnotetext{
$\square 1 \square 2 \square 3$

Fonte: Elaborado pela autora, dados da pesquisa.

(1) Bibliografias, dicionários e enciclopédias (2) Livros, Dissertações e Teses (3) Bibliografias de bibliografias, catálogos de catálogos de bibliotecas e diretórios.
}

Diante dos dados evidenciados, observa-se que os partícipes conseguem classificar as fontes de informação (Gráfico 3), ainda que se perceba uma parcela de dificuldade para distinguir fontes primárias das secundárias. Assim sendo, é salutar sugerir um aperfeiçoamento desses profissionais, visto que é através dessa classificação que se localiza sistematicamente os canais em que serão encontradas as fontes, facilitando dessa forma o acesso validado à informação. 
Numa visão geral dos resultados retratados no Gráfico 3, infere-se que os bibliotecários atuantes em bibliotecas especializadas e universitárias precisam ter clareza quanto às diferenças existentes entre as fontes de informação, que buscam atender os desejos dos usuários.

\section{Considerações finais}

As discussões sobre a competência em informação tem sido uma preocupação recorrente especialmente na última década na área de Biblioteconomia e Ciência da Informação. Assim sendo, essa investigação, ao analisar as competências em informação dos egressos do curso de Biblioteconomia do Nordeste brasileiro, constatou que, de modo geral, esses profissionais adquiriram durante seu processo formativo competências para atuar profissionalmente.

Salienta-se que, para alcançar os resultados então evidenciados, realizou-se uma revisão de literatura que possibilitou maior compreensão acerca da temática abordada, que incluiu um estudo sobre a práxis biblioteconômica, bem como sua função social, contemplando a competência em informação desses profissionais. É salutar destacar que, no Brasil, é constante a evolução dos estudos inerentes à competência em informação, entretanto, quando se reporta ao profissional da informação (bibliotecário), ainda é necessário aprofundamento de pesquisas dessa natureza, haja vista que o mercado de trabalho tem demandado desse profissional tais habilidades e atitudes na sua atividade laboral.

Considera-se que os objetivos delineados para consecução dessa investigação foram atendidos, tendo em vista que os egressos foram caracterizados (primeiro objetivo), evidenciando a sua procedência institucional quanto ao ensino básico, o conhecimento acerca do ambiente da biblioteca antes ingressar no curso de Biblioteconomia e a preocupação com a educação continuada após a conclusão do curso, com vistas ao aprimoramento de suas habilidades e competências.

Quanto ao segundo objetivo, percebeu-se que os egressos conseguem definir as necessidades informacionais, conforme orientações dos padrões da ACRL, todavia, demonstram certa dificuldade quanto à identificação e distinção entre as fontes primárias e secundárias. Entretanto, curiosamente, as fontes terciárias foram as facilmente identificadas, ainda que essas não sejam efetivamente aquelas que usualmente os bibliotecários pesquisam no cotidiano.

Nesse processo, depreende-se que o bibliotecário que desenvolve habilidades e atitudes para lidar com a informação em seus diversos ciclos, especialmente no que tange a identificação da necessidade informacional. Salienta-se, entretanto, a relevância desses profissionais se preocuparem com o aprendizado contínuo e permanente, tendo em vista as exigências explícitas da sociedade da informação.

A reflexão aqui exposta poderá fomentar um diálogo entre universidades da Região Nordeste do Brasil, no que tange a contemplar a relevância da competência em informação, não só como um conceito e temática de pesquisas, quiçá com a implementação de disciplinas que abordem com maior ênfase a temática nos Projetos Políticos-Pedagógicos dos cursos de Biblioteconomia, de acordo com a realidade de cada instituição.

Ressalta-se que o estudo não teve a pretensão de ser conclusivo, e sim trazer uma contribuição para construção do conhecimento na temática mencionada, provocando uma reflexão no campo da Biblioteconomia nordestina, quanto às competências em informação dos bibliotecários. Espera-se, ainda, que o estudo possa suscitar a conscientização desses profissionais quanto ao seu papel, a fim de que busquem o aprimoramento de suas competências, para que possam cumprir com plenitude sua missão para com a sociedade. 


\section{Referências}

ALMEIDA, C. C. de. Uma leitura dos fundamentos histórico-sociais da ciência da informação. Rev. Eletronon. Informação \& Cognição, v. 6, n. 1, p. 68-89, 2007. Disponível em: <http://www. portalppgci.marilia.unesp.br/reic/include/getdoc.php?id=213>. Acesso em: 10 out. 2013.

AMATUCCI, Marcos. Perfil do administrador brasileiro para o Século XXI: um enfoque metodológico. 2000. 295 p. Tese (Doutorado em Administração de Empresas) - Faculdade de Economia, Administração e Contabilidade, Universidade de São Paulo, São Paulo, 2000. Disponível em: <http://www.teses.usp.br/teses/disponiveis/12/12132/tde-08112010174044/Publico/TeseMarcosAmatucci.pdf>. Acesso em: 2 nov. 2013.

ASSOCIATION OF COLLEGE AND RESEARCH LIBRARIES. Information Literacy competency for higher education. Chicago: ALA, 2000. Disponível em: <http://www.ala.org/acr//ilcomstan.html>. Acesso em: 25 nov. 2013.

BORDONI, Thereza. Saber e fazer...: competências e habilidades?!? [ca. 2003]. Disponível em: $<$ http://www.pedagobrasil.com.br/pedagogia/saberefazer.htm>. Acesso em: 11 set. 2013.

BORGES, Jussara. Participação política, internet e competências infocomunicacionais: evidencias a partir de organizações da sociedade civil de Salvador. Salvador: EDUFBA, 2013. 260 p.

BOTERF, Guy. Desenvolvendo a competência dos profissionais. Porto Alegre: Artmed, 2003.

BUNDY, Alan. Australian and New Zealand Institute for Information Literacy (ANZIIL). Australian and New Zealand Information Literacy Framework; principles, standards and practice. 2ํ. Ed. Adelaide. Austrália: ANZIIL, 2004. Disponível em: <http://www.literacyhub.org/documents/InfoLiteracyFramework.pdf>. Acesso em: 19 out. 2015.

BRANDÃO, C. Rodrigues. O que é educação. São Paulo: Brasiliense, 1985.

CASTELLS, Manuel. A era da intercomunicação. Le Monde Diplomatique Brasil. 2006. Disponível em: <http://www. diplomatique.org.br/acervo.php?id=1915>. Acesso em: 18 out. 2015.

CAMPELLO, Bernadete dos Santos. A competência informacional na educação para o século XXI. In:

CAMPELLO, Bernadete et al. A biblioteca escolar: temas para uma prática pedagógica. 2. ed. Belo Horizonte: Autêntica, 2008.

COELHO, Marlene Morbeck. Competência Informacional no ambiente de trabalho: percepção do bibliotecário de órgão público, 2008. Disponível em: <http://revista.ibict.br/liinc/index.php/liinc/article/viewFile/408/281>. Acesso em: 4 dez. 2013. 
CUNHA, Murilo Bastos da. O desenvolvimento profissional e a educação continuada. Revista de Biblioteconomia de Brasília, Brasília, v. 12, n. 2, p. 145-156, jul./dez. 1984.

DELORS, Jacques. Educação: um tesouro a descobrir: relatório para a UNESCO da Comissão Internacional sobre educação para o século XXI. São Paulo: Cortez; Brasília, MEC: UNESCO, 1998.

FINE, Michelle et al. Para quem? Pesquisa qualitativa, representações e responsabilidades sociais. In: DENZIN, Norman K.; LINCOLN, Yvonna S. O planejamento da pesquisa qualitativa. 2. ed. Tradução Sandra Regina Nietz. Porto Alegre: Artmed, 2007. p. 115-140.

FLEURY, Maria Tereza Leme; FLEURY, Afonso. Construindo o conceito de

Competência. Revista de Administração Contemporânea - RAC, Edição Especial, Curitiba, ANPAD, 2001, p. 183 Disponível em: <http://www.scielo.br/pdf/rac/v5nspe/v5nspea10.pdf >. Acesso em: 10 nov. 2013.

FONSECA, Edson Nery da. Introdução à biblioteconomia. Brasília: Briquet de Lemos, 2007

FRANÇA, Ana M. M. Gestão de competências: contribuição para a definição de um modelo de competências gerenciais para o Banco do Brasil. 1998. Monografia (MBA em Recursos Humanos) - Universidade de São Paulo, São Paulo, 1998.

FREIRE, Paulo. Conscientização. São Paulo: Moraes, 1980.

HATSCHBACH, Maria Helena de Lima; OLINTO, Gilda. Competência em informação: caminhos percorridos e novas trilhas. Revista Brasileira de Biblioteconomia e Documentação: Nova Série, São Paulo, v. 4, n. 1, p. 20-34, jan. /jun. 2008.

JOHNSTON, Bill; WEBBER, Sheila. Conceptions of information literacy: new perspectives and implications. Journal of Information Science, London, v. 15, n. 6, p. 381-397, 2000.

Disponível em: <http://iis.sagepub.com/cgi/content/abstract/26/6/381>. Acesso em: 4 dez. 2013.

LE COADIC, Yves François. A Ciência da Informação. Brasília: Briquet de Lemos, 1996.

A Ciência da Informação. Tradução Yeda F. S. de Filgueiras Gomes. Brasília, DF: Biquet de Lemos, 2004.

LECARDELLI, Jane; PRADO, Noêmia Schoffen. Competência informacional no Brasil: um estudo bibliográfico no período de 2001 a 2005. Revista Brasileira de Biblioteconomia e Documentação: Nova Série, São Paulo, v. 2, n. 2, p. 21-46, dez. 2006.

MATA, Marta Leandro da. A competência informacional de graduandos de biblioteconomia da região sudeste: um enfoque nos processos de busca e uso ético da informação. Marília, 2009. Disponível em: $<$ http://www.marilia.unesp.br/Home/Pos-Graduacao/Cienciadalnformacao/Dissertacoes/mata ml me mar.pdf>. Acesso em: 10 nov. 2013. 
MUELLER, Suzana. A ciência, o sistema de comunicação científica e a literatura cientifica. In. CAMPELO, Bernadete CENDÓN, Beatriz; KREMER, Jeannette (Org.). Fontes de informação para profissionais e pesquisadores. Belo Horizonte: UFMG, 2000)

MUELLER, Susana. Literatura científica, comunicação científica.In: TOUTAIN, Lídia Maria Batista Brandão (Org.) Para Entender a Ciência da Informação. Salvador: EDUFBA, 2007. p. 125-144.

ORTEGA Y GASSET, José. Missão do bibliotecário. Brasília: Briquet de Lemos, 2006.

PROSDÓCIMO, Zulma Purês Alves; OHIRA, Maria Lourdes Blatt. Quem é o bibliotecário em exercício no Estado de Santa Catarina: necessidade de educação continuada. In: CONGRESSO BRASILEIRO DE BIBLIOTECONOMIA E DOCUMENTAÇÃO, 19., 2000, Porto Alegre. Anais... Porto Alegre, set. 2000.

SANTIAGO, Antônio Edilberto Costa. Competência informacional jurídica e as habilidades de pesquisa. 2012. $260 \mathrm{f}$. Dissertação (Mestrado em Ciência da Informação) - Instituto de Ciência da Informação, Universidade Federal da Bahia, Salvador, 2012.

SANTOS, Jaires Oliveira; BARREIRA, Maria Isabel de J. S. Perfil do bibliotecário baiano: um olhar sobre as décadas de 1980 a 2012. PAGINAS a\&b. v.3, n.1, 2014, p. 146-162. Disponível em:

$<$ http://ois.letras.up.pt/index.php/paqinasaeb/article/view/570>. Acesso em: 16 mar. 2015.

SANTOS, Jussara Pereira. O perfil do profissional bibliotecário. In: VALENTIM, Marta Pomim (Org.). Profissionais da informação: formação, perfil e atuação profissional. São Paulo: Polis, 2000.

SANTOS, Thalita Franco dos. Competências Informacionais no Ensino Superior: um estudo dos discentes de graduação em Biblioteconomia no estado de Goiás. 2011. 147 f. Dissertação (Mestrado em Ciência da Informação) - Faculdade de Ciência da Informação, Universidade de Brasília, Brasília, 2011. Disponível em:

$<$ <ttp://repositorio.unb.br/bitstream/10482/8906/1/2011 ThalitaFrancodosSantos.pdf >. Acesso em: 01 dez. 2013.

URIBE, Guilhermo Correa. Instrumento para un diagnostico organizacional en referencia a la percepción de la gestión de conocimiento y las competencias organizacionales. In: ENCUENTRO DE BIBLIOTECOLOGOS, ARCHIVISTAS Y MUSEOLOGOS, 6., 2015, Vaparaíso. Anais... Valparaíso, 2015.

VALENTIM, M. L. P. Formação do profissional da informação. São Paulo: Polis, 2002.

ZABALA, Antoni; ARNAU, Laia. Como aprender e ensinar competências. Porto Alegre: Artmed, 2010. 


\section{Dados dos autores}

\section{Jaires Oliveira Santos}

Professora na Universidade Federal da Bahia (UFBA). Atualmente coordena o Núcleo de Estágio (NUEST) do Instituto de Ciência da Informação da Universidade Federal da Bahia (ICI/UFBA). Doutoranda em Ciência da Informação pelo Programa de Pós-Graduação em Ciência da Informação da Universidade Federal da Bahia (PPGCI/UFBA). Mestra em Ciência da Informação pelo PPGCI/UFBA (2015). Possui graduação em Biblioteconomia e Documentação pela Universidade Federal da Bahia (2013). Membro do grupo de pesquisa Competências e comportamento: processos de produção, inovação e comunicação da informação (COMPORTI) da UFBA. Atuou como gestora em Bibliotecas Públicas Estaduais. Tem experiência na área de Ciência da Informação e desenvolve pesquisas com ênfase em Profissão, Competência em Informação, processo de aprendizagem e Memória.

\section{jairesoliveira@gmail.com}

\section{Maria Isabel De Jesus Sousa Barreira}

Possui graduação em Biblioteconomia e Documentação pela Universidade Federal da Bahia (1992) e Direito pela FSBA, 2014, mestrado em Ciência da Informação pela Universidade Federal da Paraíba (2001) e doutorado em Educação pela Universidade Federal da Bahia (2007). Atualmente é professor Adjunto IV da Universidade Federal da Bahia, Vice-Coordenadora do Curso de Biblioteconomia e Documentação/UFBA, Professora do Programa de Pós-Graduação em Ciência da Informação/ICI/UFBA (Mestrado e Doutorado) e dos Curso de Biblioteconomia e Arquivologia e Especialização. Membro da Comissão editoria da revista Ponto de Acesso. Tem experiência na área de Ciência da Informação, com ênfase em Ciência da Informação, atuando principalmente nos seguintes temas: biblioteca escolar, mémoria, abnt, bibliotecas comunitárias, leitura, currículo, competêencia informacional, metodologia da pesquisa e arquivo escolar.

isasousa@ufba.br

Recebido - Received: 2016-12-20

Aceitado - Accepted: 2018-12-11

\section{(cc) BY}

This work is licensed under a Creative Commons Attribution 4.0

United States License.

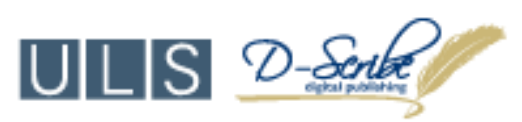

This journal is published by the University Library System of the University of Pittsburgh as part of its D-Scribe Digital Publishing Program and is cosponsored by the University of Pittsburgh Press. 